\title{
Indicações para uma espiritualidade do cuidado à luz da teologia da criação
}

\author{
João Justino de Medeiros Silva
}

\section{Introdução}

A perspectiva destas indicações é aquela da espiritualidade e da sua necessária relação com a teologia. Considerando a teologia como ato segundo, encontramos em primeiro lugar a fé. Ora a fé é, fundamentalmente, a experiência do encontro com Deus, encontro este que invade totalmente a vida a tal ponto que a existência fica marcada e transformada por este encontro. $\mathrm{O}$ exemplo das grandes conversões deixa nítido à percepção a mudança pela qual passa o convertido. Sua vida tem nova pauta, qual seja, o seguimento de Jesus. A espiritualidade cristã é a vivência espiritual de quem encontrou e abraçou o evangelho de Jesus Cristo.

Uma das funções da teologia em relação à espiritualidade é a de servir-lhe de instância crítica para a interpretação da experiência espiritual. Partindo desta compreensão de espiritualidade, aqui se encontram sete indicações inspiradas na teologia da criação que almejam ajudar a tornar mais nítida uma espiritualidade do cuidado. Certamente, muitas outras indicações poderão ser intuídas da teologia da criação. Não se trata de normas ou de regras, pois isto pouco combina com espiritualidade. Mas de indicações, traços, lembretes que venham a enriquecer a vida espiritual daqueles que crêem em Deus criador de todas as coisas.

É importante considerar que tais indicações estão formuladas como aprofundamento de alguns traços e não de superação deles. 


\section{$1^{\mathrm{a}}$ indicação: Da gratuidade à gratidão cuidadosa}

Toda a longa discussão teológico-filosófica acerca da criação que tocou o tema da criação ex nihilo aponta para o mistério da gratuidade. A célebre questão levantada por Leibniz, "por que o ser e não, antes, o nada?" tem para nós cristãos uma resposta alicerçada na compreensão de que tudo foi criado por Deus. De um lado afirma-se Deus como origem de todo o universo criado e a bondade originária de todas as criaturas superando a perspectiva dualista e, de outro, a transcendência do criador em relação às coisas criadas superando expressões de panteísmo. Esta condição de "criaturidade" do mundo implica exatamente na gratuidade da existência de todas as coisas ${ }^{1}$.

$\mathrm{O}$ ser humano, criado à imagem e semelhança de Deus, sente dentro de si o apelo a acolher a própria existência como dom. A percepção da existência como dom remete àquele que está na origem deste dom. De modo intrínseco a esta percepção apela-se ao autor de todas as coisas: Deus mesmo. A gratuidade encontra expressões de louvor àquele que tudo fez: "Quão numerosas são tuas obras, Senhor e todas fizeste com sabedoria! A terra está repleta de tuas criaturas" (Sl 103, 24).

Desponta-se aqui a gratuidade como um traço da espiritualidade do cuidado. Sabendo-se criatura, o ser humano compartilha com todas as outras criaturas da mesma condição. Existe por obra de outro, e não por si mesmo. Considerando o seu lugar central na obra da criação, o ser humano descobre o dom de todas as outras criaturas e há de configurar a gratuidade de si mesmo, como expressão de gratidão para com o Criador. Aqui poderia se aplicar a expressão evangélica "De graça recebestes, de graça dai" (Mt 10,8). A gratuidade tem uma força pedagógica, enquanto estimula os outros ao aprendizado de que não se é suficientemente agradecido ao Criador se não há cuidado pelo outro nem pelas outras coisas.

\section{$2^{\mathrm{a}}$ indicação: Da absoluta soberania do Criador ao reconhecimento dos limites do senhorio humano sobre a terra}

É do conhecimento comum dos meios teológicos a crítica da ecologia à teologia. Diante da crise ecológica que se agrava com o passar dos anos, ecólogos acusam o judeu-cristianismo de ter incutido, sobretudo entre os povos ocidentais, a confiança em um progresso crescente e ilimitado, colocando o ser humano no centro da criação com a tarefa de submeter a terra e dominar sobre os animais. Prescindindo desta discussão e recuperando uma

${ }^{1}$ J. L. RUIZ DE LA PEÑA. Teología de la creación. Santander: Ed. Sal Terrae, 1988, p. 115-116. 
visão mais relacional do ser humano com todas as outras criaturas, pode-se encontrar o corretivo de uma compreensão unilateral do domínio do ser humano sobre a natureza, recorrendo-se à afirmação da absoluta soberania do Criador. Desta forma, qualquer manifestação de senhorio da parte do ser humano há que se delimitar nos quadros relacionais. "A relação do homem com o mundo é um elemento constitutivo da identidade humana. Trata-se de uma relação que nasce como fruto da relação ainda mais profunda, do homem com Deus",2.

Logo, a teologia da criação desdobra-se em uma atitude ética de utilização equilibrada dos bens da criação em vista do ser humano, da comunhão dos homens entre si, com a natureza e com Deus. Ao "submeter a terra" de Gn 1,28 há de corresponder o "cultivar e guardar" de Gn 2,15. "Se tudo coexiste e até preexiste numa teia de relações inclusivas, a ecologia comporta, em nível humano, uma interação constante homem-natureza" ${ }^{3}$. A percepção dos limites do senhorio humano sobre a terra não há de causar um distanciamento, mas antes uma nova postura. A tradição cristã tem muito a oferecer com a singular perspectiva de Francisco de Assis, para quem todas as criaturas são irmãs. A perspectiva franciscana de uma "fraternidade cósmica" desafia para a constituição de um traço da espiritualidade do cuidado, de modo que o senhorio humano se aproxima mais da atitude cuidadosa do irmão mais velho a quem foi confiado o cuidado dos outros irmãos.

\section{$3^{\mathrm{a}}$ indicação: Do "não matarás" ao cuidado samaritano}

É inevitável que a teologia da criação esbarre com a questão do mal. "Assim, as questões que a existência do mal provoca não podem ser deixadas de lado numa reflexão teológica sobre a criação boa de Deus e sobre o ser humano criado à imagem deste Deus"4. É clássica e também popular a leitura de Gn 3 como relato que remete à teologia católica do pecado original, situando a raiz do pecado da humanidade no pecado das primeiras criaturas, Adão e Eva, pecado este de desobediência aos limites impostos pelo Criador. Há contestações quanto à precariedade desta vinculação, considerando que a afirmação de que todos os homens nascem pecadores é alheia ao autor do texto do Gênesis.

\footnotetext{
2 PONTIFÍCIO CONSELHO "JUSTIÇA E PAZ”. Compêndio da Doutrina Social da Igreja. São Paulo: Paulinas, 2005, $§ 452$.

${ }^{3}$ N. AGOSTINI, "A crise ecológica: o ser humano em questão. A atualidade da proposta franciscana" in A. S. MOREIRA (org.). Herança Franciscana. Festschrift para Simão Voigt, ofm. Petrópolis: Vozes 1996, p. 227.

${ }^{4}$ A. G. RUBIO. Unidade na pluralidade. O ser humano à luz da fé e da reflexão cristãs. São Paulo: Paulinas, 1990, p. 496.
} 
Mais recentemente, baseando-se em alguns estudos de investigação sobre a relação violência-religião, foi apresentada uma nova hipótese teológica sobre o pecado original. O pecado original se situaria propriamente no relato de Gn 4, quando do assassinato de Abel por Caim. Ali estaria o pecado original mascarado e deslocado, expressão da violação do poderoso contra o fraco ${ }^{5}$. O mandamento central do decálogo: "Não matarás!" (Ex 20,13) encontraria seu correspondente na atitude do cuidado samaritano. Em outras palavras, o imperativo ético cristão "não matarás", defende não apenas a inviolabilidade da vida humana, mas também o cuidado pela vida, nas suas mais desafiadoras expressões.

\section{$4^{\mathrm{a}}$ indicação: Do trabalho como participação na obra criadora ao traba- lho como expressão de cuidado pela vida}

O trabalho é uma realidade humana de fundamental valor. Expressa a condição histórica do ser humano enquanto criador de cultura. Pensar o ser humano implica reconhecê-lo na sua condição de quem interfere na natureza transformando-a em cultura. A teologia da criação sem querer se tornar uma teologia do trabalho indica que o ser humano recebe de Deus as obras criadas e é chamado a unir-se à ação criadora divina mediante o trabalho. Antes de o pecado macular o sentido original do trabalho, o Criador já dera ao homem as ordens de cuidado do Jardim (Gn 2,15). A administração do mundo confiada ao ser humano é uma indicação desse desejo divino de que aquele que foi criado à sua imagem e semelhança expresse uma dimensão dessa imagem pela continuidade da própria obra criadora. Ainda assim, afirma-se que "o trabalho é um valor da vida humana, mas não é o único nem o supremo valor. O ser humano é chamado a trabalhar porque é criado à imagem do Deus criador, mas o trabalho não esgota o significado da vida humana nem o sentido da história da humanidade."

A referência ao descanso do Criador - "Deus abençoou o sétimo dia e o santificou, pois nele descansou depois de toda a obra da criação" (Gn 2,3) - sinaliza a limitação do próprio trabalho, ou seja, aponta o sentido do trabalho para além de si mesmo, como outrora afirmado. Parece indicar que o ser humano, que pode muito pelo trabalho, não pode tudo. O descanso mostranos como as forças humanas são finitas e como o trabalho tem seus limites. No mundo contemporâneo, organizado ao redor do trabalho, a expressão do

\footnotetext{
${ }^{5}$ Vale a leitura do artigo de L. C. SUSIN. "Sou eu, acaso, guarda do meu irmão? Uma nova hipótese teológica sobre o 'pecado original'." in REB (2005) p. 5-24.

${ }^{6}$ A. G. RUBIO. Unidade na pluralidade. O ser humano à luz da fé e da reflexão cristãs. São Paulo: Paulinas, 1990, p. 347-348.
} 
pecado se manifesta pelas variadas formas de escravidão, trabalho forçado, desemprego, subemprego, salários insuficientes e defasados. É de suma importância garantir para o ser humano - homem e mulher - a experiência do trabalho como co-criação. Assim, como co-criador, o ser humano tem mais chances de tocar o sentido da transcendência do próprio trabalho e este haveria de ser expressão de cuidado pela vida.

As necessidades fundamentais do ser humano como alimentação, vestuário, moradia não deveriam ser os primeiros frutos do trabalho? Toda atividade no horizonte do trabalho deveria nos comprometer mais com a defesa da vida e lembrar-nos que "os direitos dos trabalhadores, como todos os demais direitos, se baseiam na natureza da pessoa humana e na sua dignidade transcendente" .

\section{$5^{\text {a }}$ indicação: Da pluralidade da criação à unidade no cuidado pela di- versidade}

Os relatos bíblicos da criação estão repletos de indicações da pluralidade das criaturas: "Deus disse: que a terra verdeje de verdura: ervas que dêem semente e árvores frutíferas que dêem sobre a terra, segundo sua espécie, frutos contendo sua semente" e assim se fez. Deus disse: "Fervilhem as águas um fervilhar de seres vivos e que aves voem acima da terra, sob o firmamento do céu, e assim se fez" (Gn 1,11.20). O que hoje se chama biodiversidade é um fato da criação. Quando nos damos conta da riqueza das espécies aproximamo-nos do indescritível, pois quanto ainda há por ser descoberto no reino animal e no reino vegetal.

Em se tratando do ser humano esta diversidade é bem maior, pois entram tantas outras variáveis: geográficas, climáticas, históricas, lingüísticas, políticas, sociais e culturais. Neste campo, o que ainda se pode conhecer é infinitamente maior que o já conhecido. Por mais globalizado que seja, o mundo contemporâneo é iniciante no contato com a diversidade dos povos. É impossível o conhecimento total da diversidade, mesmo sabendo que o desconhecimento não denota, necessariamente, a negação da riqueza e da pluralidade da criação e da cultura. A variedade e a riqueza das culturas atestam a pluralidade da criação como ponto de partida para uma pluralidade cultural (e religiosa!) em oposição a modelos culturais homogêneos ${ }^{8}$.

\footnotetext{
7 PONTIFÍCIO CONSELHO "JUSTIÇA E PAZ". Compêndio da Doutrina Social da Igreja. São Paulo: Paulinas, 2005, § 301.

${ }^{8}$ Que conhecemos dos quenianos, escolhidos aqui a título de exemplo: "No caso dos quenianos se, por um lado, o incipiente transporte público e o dispendioso transporte privado obrigam-nos a caminhar uma dezena de quilômetros diariamente, por outro lado, o andar solitário
} 
O cuidado para que a diversidade seja preservada depende também da atitude espiritual de valorização da unidade na pluralidade. Espiritualmente é preciso conter o desejo da uniformidade que mata a riqueza originária da criação e das culturas e abrir-se a expressões generosas de acolhimento de tudo o que ainda pode vir a ser conhecido.

\section{$6^{a}$ indicação: Da kênosis do divino ao esvaziamento humano como cui- dado de si}

Haveria, segundo a tradição rabínica, uma kênosis do Pai que ao criar, contrai-se, para dar espaço à criação. $\mathrm{O}$ auge da criação se daria na encarnação. O Verbo de Deus assume a humanidade criada esvaziando-se de si mesmo no movimento kenótico (F1 2,7). Deus abraça a criação de um modo singular, enquanto a natureza humana (criada) e a natureza divina (incriada) subsistem na pessoa do Verbo. "A criação encontra em Cristo a sua chave de compreensão, o seu destino, a sua bondade. E também a sua salvação..." Nas palavras do hino de Paulo segundo a Epístola aos Colossenses, "porque nele foram criadas todas as coisas, nos céus e na terra... tudo foi criado por ele e para ele" $(1,16)$. Paradoxalmente, o auge da criação coincide com o esvaziamento de Deus.

Tantas vezes entendemos a espiritualidade como assimilação de conteúdos, de práticas, de sabedoria que vão sendo acumulados em nós. Cuidamos de nos "encher". Ora, uma espiritualidade kenótica, em sintonia com os grandes místicos da tradição cristã, não pediria um cuidado de si pautado mais no esvaziamento que no preenchimento? A sociedade de consumo conduz-se na contramão do esvaziamento enquanto seus lemas são "ter mais", "ajuntar mais", "trocar pelo mais novo", "descartar o que já não serve e adquirir novos modelos". Cada pessoa é vista como potencial consumidor. Os senhores do mercado, de plantão por " 24 horas", encontram formas de tudo transformar em mercadorias. A sobriedade, como uma das marcas da espiritualidade cristã, clama a favor de um estilo de vida simples e não consumista.

e silencioso lhes permite o processamento de invejável estética interior, estampada no espírito de determinação e em seus corpos esguios, de traços precisos, esculturais. Um outro mundo, antes necessário e também possível, depende muito da contribuição da África, portadora das maiores reservas de resistência e esperança do planeta". A. BRIGHENTI, "Espiritualidade para outro mundo possível”, in Perspectiva Teológica 39 (2007) p. 248.

${ }^{9}$ L. C. SUSIN. "O Pai e poeta da criação" in G. L. B. HACKMANN (org.) Deus Pai. Porto Alegre: EDIPUCRS, 1999, p. 62. 


\section{$7^{\mathrm{a}}$ indicação: Do cuidado com as espécies eucarísticas ao cuidado com os membros do Corpo de Cristo}

A eucaristia, sacramento e presença real de Cristo nas espécies do pão e do vinho, dá-se nesses elementos da criação. O Papa Bento XVI, na Exortação Sacramentum Caritatis lembra como

“... nos educa a própria liturgia quando o sacerdote, durante a apresentação dos dons, dirige a Deus uma oração de bênção e súplica a respeito do pão e do vinho, "fruto da terra", "da videira" e do "trabalho do homem". Com essas palavras, o rito, além de envolver na oferta a Deus toda a atividade e realização humana, impele-nos a considerar a terra como criação de Deus, que produz quanto precisamos para nosso sustento. [...] As condições ecológicas em que a criação subjaz em muitas partes do mundo suscitam justas preocupações, que encontram motivo de conforto na perspectiva da esperança cristã, pois esta compromete-nos a trabalhar responsavelmente na defesa da criação; de fato, na relação entre a Eucaristia e o universo, descobrimos a unidade do desígnio de Deus e somos levados a individuar a relação profunda da criação com a "nova criação" que foi inaugurada na ressurreição de Cristo, novo Adão..."

Cresce entre nós a consciência das implicações sociais da fé eucarística. Neste sentido, somos desafiados a estender o cuidado que temos com as espécies eucarísticas aos membros do Corpo de Cristo, isto é, aos homens e mulheres que do Corpo de Cristo participam pelo batismo e de todos os outros que são ordenados a participar deste mesmo Corpo. A reverência à Eucaristia não pode estar dissociada do cuidado pela criação. João Paulo II compreendia como critério para comprovar a autenticidade de nossas celebrações eucarísticas o empenho para superação de tantas pobrezas do nosso mundo ${ }^{11}$.

\footnotetext{
${ }^{10}$ BENTO XVI. Exortação Apostólica Pós-sinodal Sacramentum Caritatis. São Paulo: Paulinas, $2007, \S 92$.

${ }^{11}$ JOÃO PAULO II. Mane nobiscum Domine. São Paulo: Paulinas, 2004, p. 32.
} 


\section{Conclusão}

Concluímos estas indicações com um poema de Murilo Mendes. Intitula-se Salmo $n^{\circ} 3$ e é de uma beleza muito particular. O poeta parte da grandeza da obra da criação para chegar ao mistério da presença divina na eucaristia. A sensibilidade do poeta contrasta com nossos discursos teológicos tão longos. Uma espiritualidade do cuidado não descuida da presença de Deus nas coisas pequenas.

\section{Salmo n 3}

Murilo Mendes

Eu te proclamo grande, admirável,

Não porque fizeste o sol para presidir o dia

$E$ as estrelas para presidirem a noite;

Não porque fizeste a terra e tudo que se contém nela,

Frutos do campo, flores, cinemas e locomotivas;

Não porque fizeste o mar e tudo o que se contém nele,

Seus animais, suas plantas, seus submarinos, suas sereias:

Eu te proclamo grande e admirável eternamente

Porque te fazes minúsculo na eucaristia,

Tanto assim que qualquer um, mesmo frágil, te contém. ${ }^{12}$

\section{Referências Bibliográficas}

AGOSTINI, N. "A crise ecológica: o ser humano em questão. A atualidade da proposta franciscana" in A. S. MOREIRA (org.). Herança Franciscana. Festschrift para Simão Voigt, ofm. Petrópolis: Vozes, 1996.

BENTO XVI. Exortação Apostólica Pós-sinodal Sacramentum Caritatis. São Paulo: Paulinas, 2007.

BRIGHENTI, A. "Espiritualidade para outro mundo possível", in Perspectiva Teológica 39 (2007) 247-256.

JOÃO PAULO II. Carta Apostólica Mane nobiscum Domine. São Paulo:

Paulinas, 2004.

MENDES, M. Melhores poemas. Seleção de Luciana Stegagno Picchio. São Paulo: Global, 2000.

PONTIFÍCIO CONSELHO "JUSTIÇA E PAZ". Compêndio da Doutrina Social da Igreja. São Paulo: Paulinas, 2005.

\footnotetext{
${ }^{12}$ M. MENDES, Melhores poemas. Seleção de Luciana Stegagno Picchio. São Paulo: Global, 2000 , p. 56.
} 
RUBIO, A. G. Unidade na pluralidade. O ser humano à luz da fé e da reflexão cristãs. São Paulo: Paulinas, 1990.

RUIZ DE LA PEÑA, J. L. Teología de la creación. Santander: Ed. Sal Terrae, 1988.

SUSIN, L. C. "O Pai e poeta da criação" in G. L. B. HACKMANN (org.) Deus Pai. Porto Alegre: EDIPUCRS, 1999, 39-74.

. "Sou eu, acaso, guarda do meu irmão? Uma nova hipótese teológica sobre o 'pecado original'." in REB (2005) 5-24.

\title{
Resumo
}

Com inspiração na teologia da criação, são apresentadas breves indicações com o objetivo de tornar mais nítida uma espiritualidade do cuidado. Não se trata de normas ou de regras, mas de indicações para enriquecer a vida espiritual dos que crêem em Deus criador de todas as coisas e desejam uma sociedade mais fraterna e responsável.

Palavras-chave: Criação, Espiritualidade, Cuidado.

\begin{abstract}
Searching for inspiration in the theology of creation, this article presents some indications to become clearer a spirituality of care. There are no norms or rules, but only indications to enrich the spiritual life of those who believe in God, the Creator of all things, and search for a more fraternal and responsible society.
\end{abstract}

Keywords: Creation, Spirituality, Care.

João Justino de Medeiros Silva

Doutor em Teologia pela Universidade Gregoriana Coordenador e professor do Curso de Teologia do CES/ITASA

Artigo Recebido em 11/11/2010

Artigo Aprovado em 15/12/2010 